\title{
Growth Rate Studies of Diamondback Moth, Plutella xylostella in Different Geographical Regions of North India
}

\author{
A. Kumar*, R.S. Rana, K.C. Sharma, V.G.S. Chandel and M. Kaur \\ Dr Y.S. Parmar University of Horticulture and Forestry, Department of Entomology, \\ Nauni, Solan-173230 (Himachal Pradesh), India \\ *Corresponding author
}

\author{
A B S T R A C T
}

\begin{tabular}{|c|}
\hline Keywords \\
\hline $\begin{array}{l}\text { Geographical } \\
\text { localities, Life } \\
\text { fertility, intrinsic } \\
\text { rate, Plutella } \\
\text { xylostella. }\end{array}$ \\
\hline Article Info \\
\hline $\begin{array}{l}\text { Accepted: } \\
10 \text { September } 2017 \\
\text { Available Online: } \\
10 \text { October } 2017\end{array}$ \\
\hline
\end{tabular}

Keywords

Geographical localities, Life fertility, intrinsic rate, Plutella

Article Info

Accepted:

Available Online:

\section{Introduction}

The diamondback moth, Plutella xylostella (L.), in India and throughout world is the most catastrophic pest of vegetable crops belonging to family brassicaceae (Niu et al., 2013; Kianpour et al., 2014). The first instar larvae mine in the leaf and the subsequent instars feed on the leaf and skeletonize it ultimately affecting the plant growth and rendering it unfit for further use. In India, its infestation leads to $30-100 \%$ loss of the cole crops (Ahmed et al., 2009). It is estimated that 4 to 5 billion USD every year was wasted due to management cost and yield losses around the world (Furlong et al., 2013). There is differences in the biological activities of the diamondback moth when fed on different host plants (Zhang et al., 2012; Niu et al., 2014) and on different climatic conditions and temperatures (Liu et al., 2003; Golizadeh et al., 2007), there is a less literature pertaining on intra-specific variations of $P$. xylostella when reared on the same host plant (Pan et al., 2014). Gathering this data will be useful to understand the population variations in different areas with the goal that develop suitable management techniques (Ram et al., 2016). In view of the above, the present study was conducted to understand genetic variation of diamondback moth. 


\section{Materials and Methods}

\section{Host plant}

Cauliflower seeds were shown in the open field at the experimental farm of the department of Entomology, Dr Yashwant Singh Parmar university of Horticulture and Forestry (Nauni, Solan, HP, India). Transplanting was done after 4 weeks, when the plants had 4-5 leaves, individually in open field for use in the following experiments.

\section{Sampling}

Larvae, pupae and adults from four different geographical areas of North India viz. Hisar (Haryana), Delhi (UT), Pantnagar (Uttarakhand) and Saharnpur (Uttar Pradesh) of different altitudes (Table 1) from the cauliflower and cabbage fields at each location were collected manually and were immediately placed in plastic jar $(20 \mathrm{~cm} \times 10$ $\mathrm{cm}$ ), top of which was covered with muslin cloth with leaves of cauliflower inside the container as food to the developing larvae.

About 9-10 generations of $P$. xylostella adults were reared on the same cauliflower variety in the laboratory. The adults thus emerged were fed with $10 \%$ sugar syrup in cotton swab and were provided with fresh cauliflower leaves for egg laying. Male-female pairs were placed in cages of size of $36 \times 34 \times 24 \mathrm{~cm}$ with glass pan on three sides in order to get the same aged eggs of test insect. Fresh leaves of cauliflower with their petiole dipped in glass vials $(7 \mathrm{~cm} \times 1.5 \mathrm{~cm})$ were kept inside these cages. The cauliflower leaves were removed from the rearing cage after $12 \mathrm{~h}$, eggs were moved individually into a petri dish that contained a cauliflower leaf (around 25 $\mathrm{cm}^{2}$ ). Until pupation the larvae were raised in the petri dish, and the pupae were transferred to rearing cage. To check sex ratio, female fecundity and adult longevity the emerged adults were reared as described above till all females and males died. The culture of the test insect collected from each locality was maintained under laboratory conditions at room temperature $\left(25 \pm 1^{\circ} \mathrm{C}\right)$ throughout the period of study.

\section{Life-table study}

Life-fertility study were conducted in a growth chamber $\left[25 \pm 1^{\circ} \mathrm{C}, 65 \% \mathrm{RH}\right.$ with a photoperiod of 14:10 (L: $\quad$ D) h]. The observation on egg hatching was daily recorded, and the numbers of hatched were recorded until either the eggs hatched or the eggs crumbled. Freshly hatched larvae from the stock culture were transferred into a petri dish containing cauliflower leaves. New leaves were placed daily in place of old leaves until the larvae died or pupated. Daily observation was taken on larval, pupal, and adult stages until development was complete. To differentiate different larval instars exuviae were used. Single pair was kept in a plastic drum with a 4-5 leaf cauliflower leaves for mating. The adults were fed on cotton swab with $10 \%$ honey solution regularly. Cauliflower leaves were replaced with new leaves daily, and eggs deposited on each plant and drum walls were collected with the help of camel hair brush and recorded daily until the female died. The data is so collected used for calculating the intrinsic rate of increase (rm), mean generation time (T), finite rate increase $(\lambda)$, doubling time (DT) and net reproductive rate (Ro).

\section{Results and Discussion}

Results Life fertility parameters of different $P$. xylostella populations have been represented in Table 2. Newly hatched egg which survive to age $\mathrm{x}$ marked as $\mathrm{lx}$ and the peak value of $\mathrm{mx}$ demonstrated a quick increment to the maximum, and a more clearly characterized could be recognized in 
the beginning of adult emergence (Figures 1, 2, 3 and 4). The data reveals that there were observable differences in the different populations with respect to their life fertility parameters. The gross reproductive rate (GRR) was highest in the Saharanpur population (170.68 female eggs per female) and minimum was for Pantnagar 123.58. The net reproductive rate (Ro) followed almost similar trend as the Saharanpur population had highest value of Ro followed by Pantnagar and Hisar i.e. 76.41, 63.25 and 62.74females produced per generation, respectively. The Delhi population had the least Ro value (56.31females produced per generation). The approximate generation time (Tc) varied from 19.58 days in Saharanpur population to 22.63 days in Hisar population. The Gross fecundity (Mx) was highest for Saharnpur population (316.13 eggs per female) and least $\mathrm{Mx}$ was observed in the Delhi population i.e. 223.44 eggs per female. The innate capacity for increase (rc) was highest in the Saharanpur and Hisar population had lowest rc value. The intrinsic rate of natural increase (rm) was calculated from rc values for different populations. Similarly highest value of rm value was observed in the Saharanpur. The least value of $\mathrm{rm}$ was observed in the Hisar population. On comparing fertility parameters of $P$. xylostella of different populations, it was found that the Saharanpur population was the most prolific among all the populations while the Hisar population was the least prolific as revealed by the minimum value of the true intrinsic rate of increase amongst all the populations. The true generation time $(\mathrm{T})$ and Doubling time (DT) were minimum for Saharanpur population and maximum for Hisar population. Weekly multiplication rate (WM) was observed to be the highest for the Sharanpur population (5.07 days) and least for Hisar population (3.75 days).

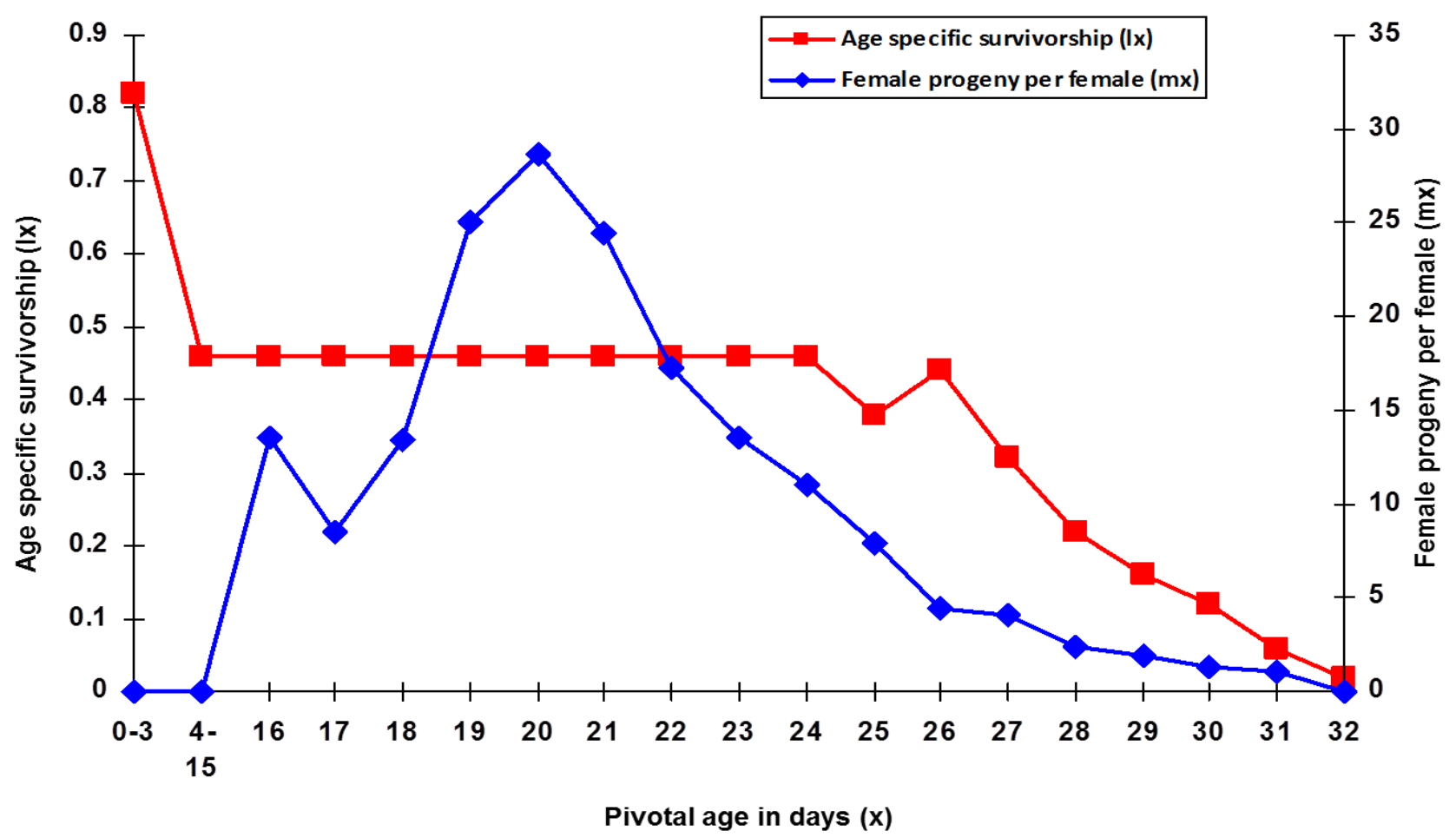

Fig. 1. Age specific survival and fecundity for $P$. xylostella collected from Sharanpur 


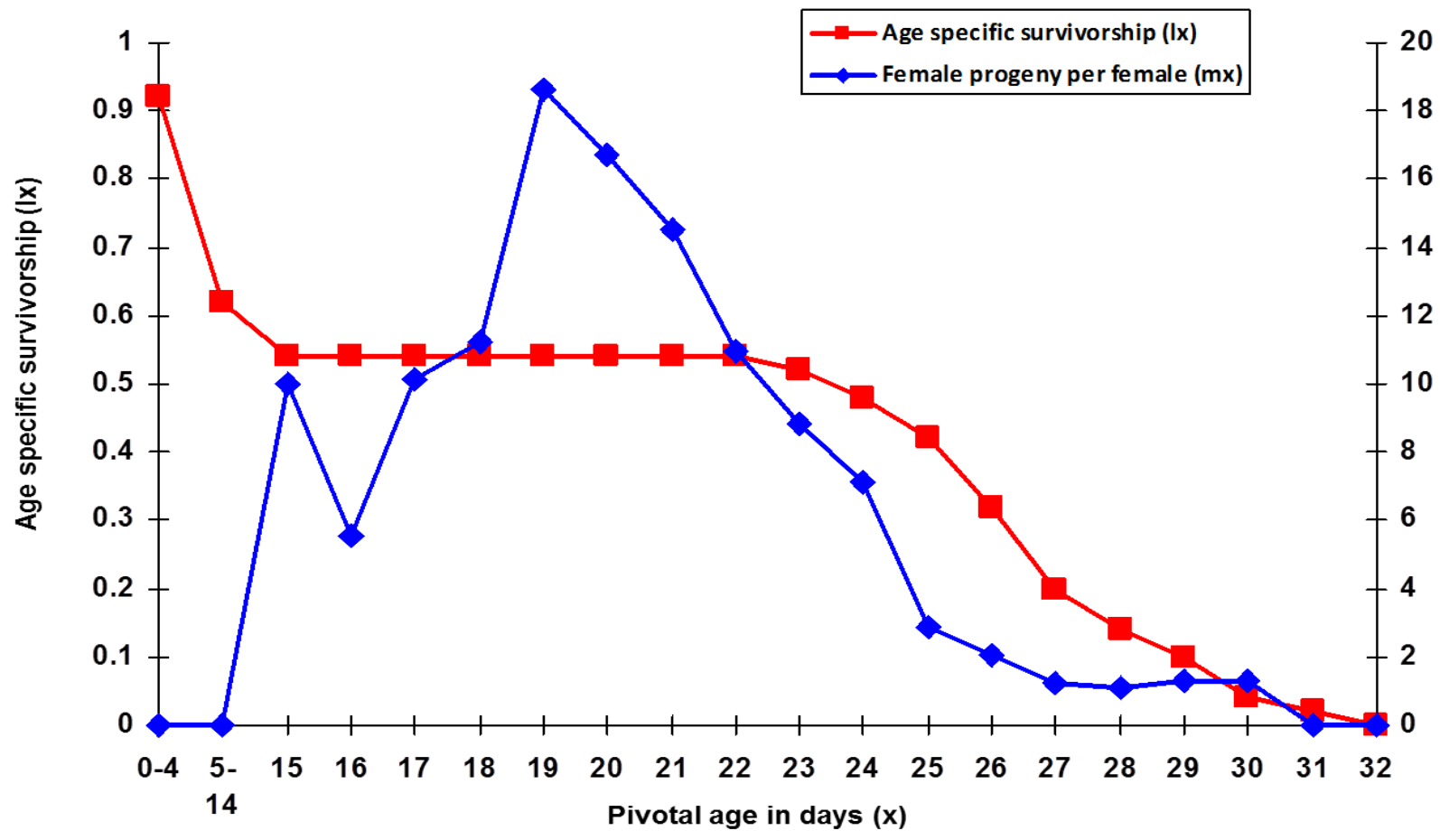

Fig. 2. Age specific survival and fecundity for $P$. xylostella collected from Pantnagar

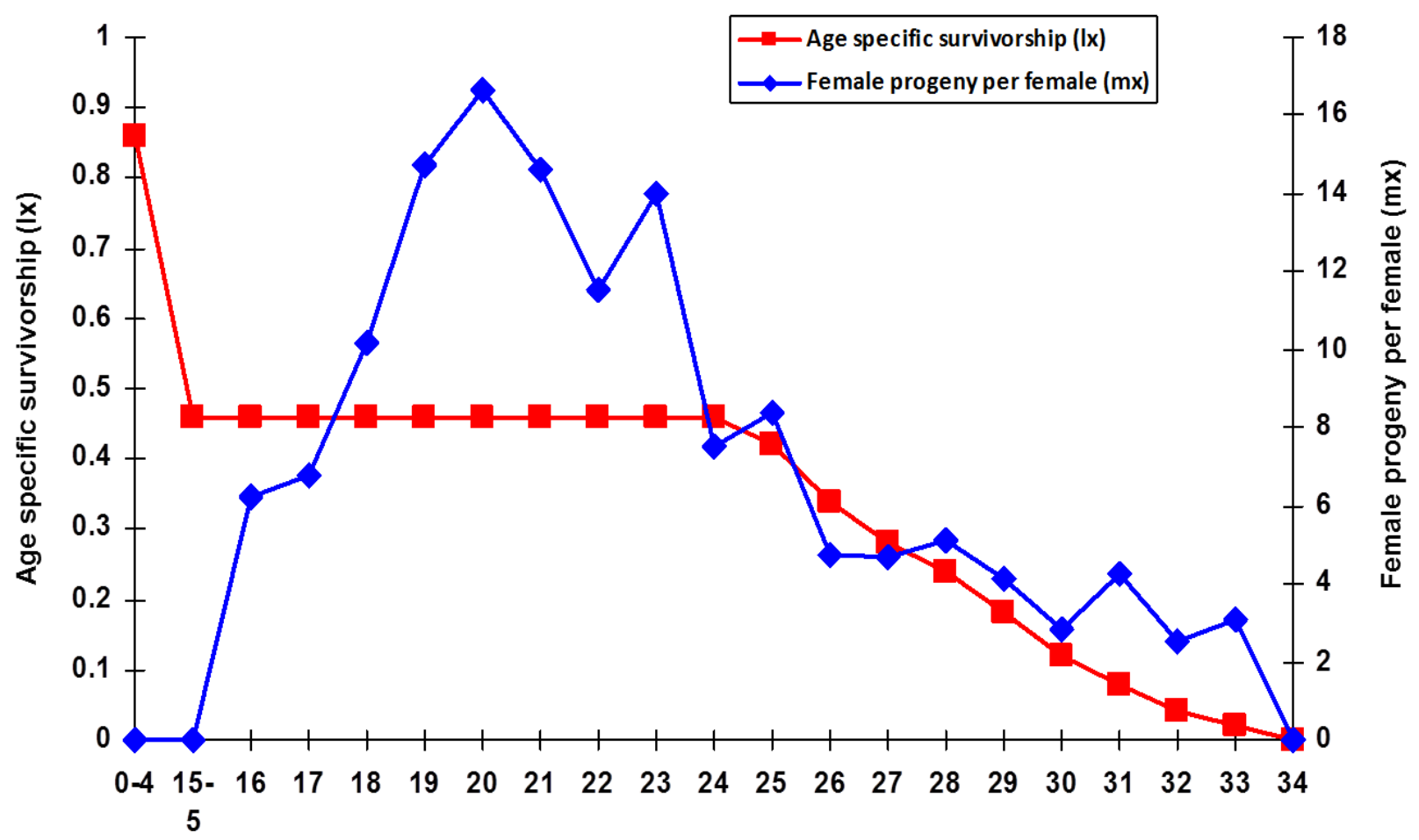

Pivotal age in days $(x)$

Fig. 3. Age specific survival and fecundity for $P$. xylostella collected from for Delhi population 


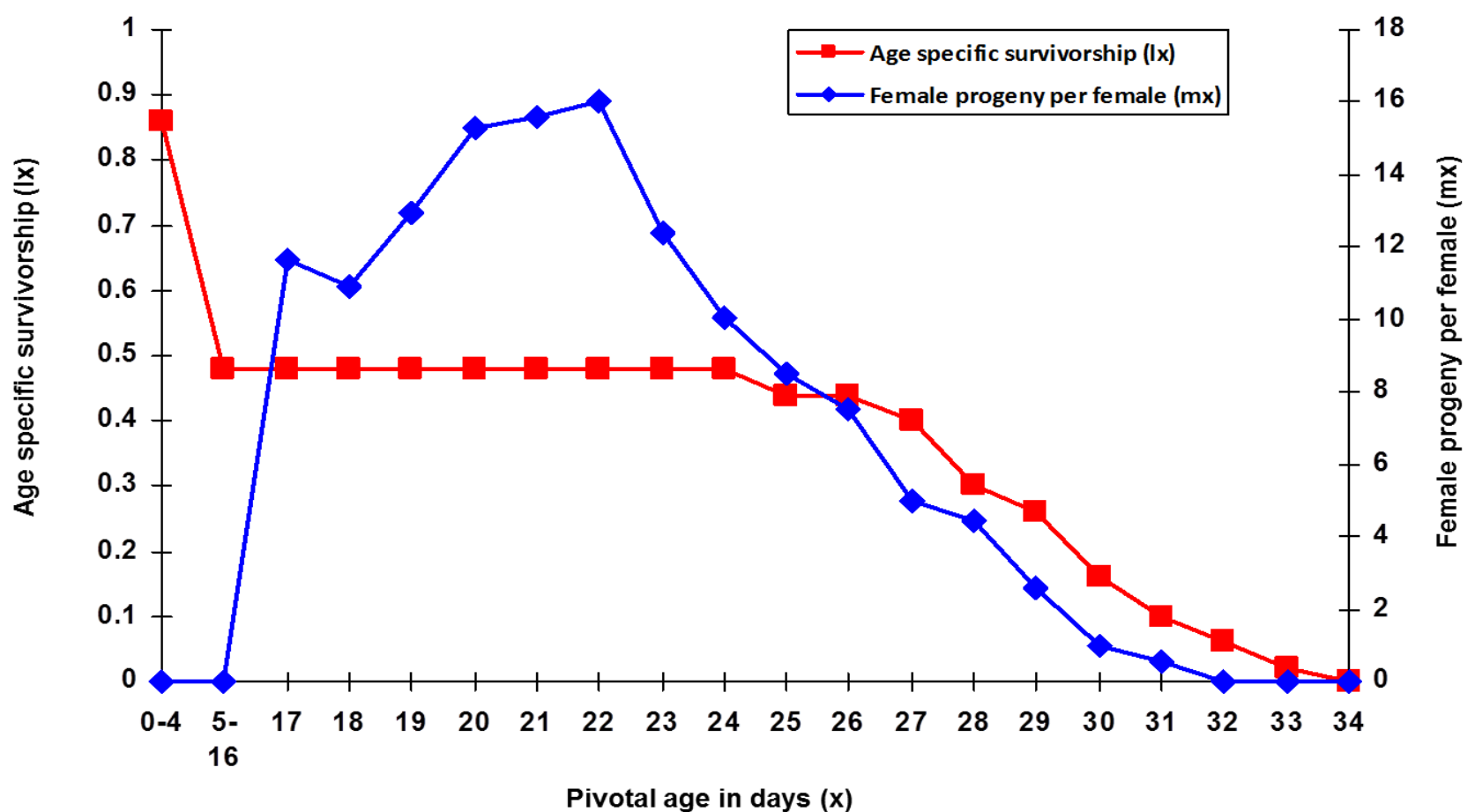

Fig. 4. Age specific survival and fecundity for $P$. xylostella collected from Hisar

Table.1 Sampling localities of Plutella xylostella

\begin{tabular}{|c|c|}
\hline Locality & Altitude (feet) \\
\hline Sharanpur (Uttar Pradesh) & 885 \\
\hline Pantnagar(Uttarakhand) & 764 \\
\hline Delhi (UT) & 709 \\
\hline Hisar(Haryana) & 705 \\
\hline
\end{tabular}

Table.2 Comparative life table parameters of different populations of Plutella xylostella

\begin{tabular}{|c|c|c|c|c|}
\hline & \multicolumn{4}{|c|}{ Fertility parameters of DBM in the indicated population } \\
\hline Parameters & Saharanpur & Pantnagar & Delhi & Hisar \\
\hline Gross reproductive rate (GRR) & 178.68 & 123.58 & 142.06 & 140.47 \\
\hline Net reproductive rate $\left(\mathbf{R}_{\mathbf{0}}\right)$ & 76.41 & 63.25 & 56.31 & 62.74 \\
\hline Approximate generation time $\left(\mathbf{T}_{\mathrm{c}}\right)$ & 19.58 & 19.75 & 21.34 & 22.63 \\
\hline Innate capacity for increase $\left(r_{c}\right)$ & 0.221 & 0.210 & 0.189 & 0.183 \\
\hline Intrinsic rate of natural increase $\left(r_{m}\right)$ & 0.232 & 0.218 & 0.195 & 0.189 \\
\hline True generation time $(\mathbf{T})$ & 18.69 & 19.02 & 20.67 & 21.90 \\
\hline Finite rate of increase $(\lambda)$ & 1.26 & 1.24 & 1.22 & 1.21 \\
\hline Doubling time (DT) & 2.99 & 3.18 & 3.56 & 3.67 \\
\hline Weekly multiplication rate (WM) & 5.07 & 4.60 & 4.92 & 3.75 \\
\hline Gross fecundity $\left(\mathbf{M}_{\mathbf{x}}\right)$ & 316.13 & 223.44 & 251.33 & 259.33 \\
\hline
\end{tabular}


These differences can be attributed to thermal adaptations to different geographical areas. The acclimatization of the pest population from distinct geographical areas may also be the reason for such differences. So it seems reasonable to speculate that the differences among the populations may be associated with their adaptation to their respective local climatic conditions. There is a difference in development (from neonate to adult) in the test insect when reared on different temperature (Golizadeh et al., 2007). Other than environmental variability are vital components for nearby adjusting among allopatric areas and biological difference has been found along latitudinal gradient (Lee and Michall-Old, 2011). Since P. xylostellais exceptionally tolerant to various insecticides and it has been discovered that resistance is area specific, being identified with the host plants, social practices, insecticide application example and advancements in various geological areas (Mohan and Gujar, 2003). So learning of contrasts in $P$. xylostella population diverse geological areas could give understanding into population progression and be utilized adequately for precisely anticipating $P$. xylostella population advancement in various locations keeping in mind the end goal to choose techniques and basic planning for management as reported by Pan et al., (2014) while studying such phenomenon in $P$. xylostella from five different geographical locations in China. Similar results were recorded for $P$. xylostella by Ram et al., (2016), who reported difference in $\mathrm{rm}$ value in the five populations of diamondback moth collected from different regions having different altitudes viz. Hisar, Kangra, Solan, Theog and Kinnaur. The $\mathrm{r}_{\mathrm{m}}$ value was found to be maximum $(0.222$ female progeny/female/day) for the Kangra, whereas for the Kinnaur, Theog, Solan and Hisar population it was $0.203,0.202,0.182$ and 0.151 female progeny/female/day. Natural rate of increase $(\mathrm{rm})$ would reflect many factors, for example, fertility, survival rate, and generation time. These qualities would satisfactorily summarize the physiological characteristics of a species in connection to its ability to multiply. To assess the performance of an insect, it would be a most suitable parameter (Southwood and Henderson, 2009). Since the biology fluctuates with land source, hereditary techniques, the relative rate of natural determination and hereditary separation ought to be utilized to investigate the topographical variation of $P$. xylostella.

\section{References}

Ahmed, T., M. Ansari, and H. Ali, 2009. Outbreak of diamondback moth, Plutella xylostella in Aligarh, India. Trends in Bioscience, 2(1):10-12

Furlong, M.J., D. J. Wright and L. M. Dosdall, 2013. Diamondback moth ecology and management: problems, progress, and prospects. Annual Review of Entomology, 58:517-541.

Golizadeh, A., K., Karim, Y. Fathipour and H. Abbasipour, 2007. Temperaturedependent development of diamondback moth, Plutella xylostella (Lepidoptera: Plutellidae) on two brassicaceous host plants. Insect Science, 14:309-316.

Kianpour, R., Y. Fathipour, J. Karimzadeh, and V. Hosseininaveh, 2014. Influence of different host plant cultivars on nutritional indices of Plutella xylostella (Lepidoptera: Plutellidae). Journal of Crop Protection, 3(1): 43-49.

Lee, C.R., and T. Mitchell-Olds, 2011. Quantifying effects of environmental and geographical factors on patterns of genetic differentiation. Molecular Ecology, 20:4631-4642.

Liu, T. X., W. D. Hutchison, W. Chen, and E. C. Burkness, 2003. Comparative susceptibilities of diamondback moth 
(Lepidoptera: Plutellidae) and cabbage looper (Lepidoptera: Noctuidae) from Minnesota and South Texas to lambdacyhalothrin and indoxacarb. Journal of Economic Entomology, 96(4): 12301236

Mohan, M., and G. T. Gujar, 2003. Local variation in susceptibility of the diamondback moth, Plutella xylostella (Linnaeus) to insecticides and role of detoxification enzymes. Crop Protection, 22:495-504.

Niu, Y.Q., X.W. Li, P. Li and T.X. Liu. 2013. Effects of different cruciferous crops on the fitness of Plutella xylostella (Lepidoptera: Plutellidae). Crop Protection, 54:100-105.

Niu, Y.Q., Y. X.Sun and T.X. Liu, 2014. Development and reproductive potential of diamond blackmoth (Lepidoptera: Plutellidae) on selected wild crucifer species. Environmental Entomology, 43:69-74.
Pan, Q.J., L.C. Xiao, L. Lin, J. Thomas, R. Smith and T.X. Liu, 2014. Geographical variations in life histories of Plutella xylostella in China. Journal of Pest Science, 87:659-670.

Ram, B., Sharma, K.C., N. Devi, and V.G.S. Chandel. 2016. Studies on intra-specific variations in the diamondback moth, Plutella xylostella (Lepidoptera: Yponomeutidae) under different geographical regions. Journal of Applied and Natural Science, 8(3): 1629-1633.

Southwood, T.R.E., and P.A. Henderson, 2009. Ecological methods, 3rd edn. Methuen, London

Zhang, P.J., Y.B. Lu, M.P. Zalucki, and S.S. Liu, 2012. Relationship between adult oviposition preference and larval performance of the diamondback moth, Plutella xylostella. Journal of Pest Science, 85:247-252.

\section{How to cite this article:}

Kumar, A., R.S. Rana, K.C. Sharma, V.G.S. Chandel and Kaur, M. 2017. Growth Rate Studies of Diamondback Moth, Plutella xylostella in Different Geographical Regions of North India. Int.J.Curr.Microbiol.App.Sci. 6(10): 986-992. doi: https://doi.org/10.20546/ijcmas.2017.610.119 